\title{
Real-world effectiveness of second-line Afatinib versus chemotherapy for the treatment of advanced lung squamous cell carcinoma in immunotherapy-naïve patients
}

You-Yi Chen ${ }^{1,2}$, Shih-Chieh Chang ${ }^{3}$, Cheng-Yu Chang ${ }^{4}$, Chun-Fu Chang ${ }^{3}$, Yi-Chun Lai ${ }^{3}$, Yu-Feng Wei ${ }^{5,6}$ and Chung-Yu Chen ${ }^{1,2^{*}}$

\begin{abstract}
Background: Limited treatment options exist for relapsed advanced lung squamous cell carcinoma (SCC), leading to poor outcomes compared with adenocarcinoma. This study aimed to investigate the efficacy of second-line afatinib versus chemotherapy in patients with advanced lung SCC who progressed after first-line chemotherapy.

Methods: In this retrospective, multisite cohort study, we recruited patients with initial locally advanced or metastatic lung SCC from four institutes in Taiwan between June 2014 and October 2020. The primary endpoint of this study was progression-free survival (PFS), and the secondary endpoints were the objective response rate (ORR), disease control rate (DCR), and overall survival (OS).
\end{abstract}

Results: The present study enrolled 108 patients: 19 received second-line afatinib, and 89 received second-line chemotherapy. The median ages were 71 and 67 years, respectively. PFS was significantly longer among patients who received afatinib than among those who received chemotherapy (median 4.7 months [95\% confidence interval (Cl), 0.1-7.5] vs. 2.6 months [95\% Cl, 0.9-6.7]; hazard ratio (HR) 0.53 [95\% Cl 0.32-0.88], $p=0.013$ ). Compared with the chemotherapy group, OS was longer in the afatinib group but did not reach significance (median 16.0 months [95\% Cl, 6.1-22.0] vs. 12.3 months [6.2-33.9]; HR 0.65 [95\% Cl 0.38-1.11], $p=0.112$ ).

Conclusions: Afatinib offered a longer PFS and comparable OS to chemotherapy in advanced lung SCC patients in a real-world setting, it may be considered as a 2 nd line alternative treatment choice for immunotherapy unfit advanced lung SCC patients.

Keywords: Afatinib, Lung squamous cell carcinoma, Second-line treatment

\footnotetext{
* Correspondence: c8101147@ms16.hinet.net

${ }^{1}$ Division of Pulmonary and Critical Care Medicine, Department of Internal

Medicine, National Taiwan University Hospital Yunlin Branch, Yunlin Count,

Douliu City, Taiwan, Republic of China

${ }^{2}$ College of Medicine, National Taiwan University, Taipei, Taiwan

Full list of author information is available at the end of the article
}

C C The Author(s). 2021 Open Access This article is licensed under a Creative Commons Attribution 4.0 International License, which permits use, sharing, adaptation, distribution and reproduction in any medium or format, as long as you give appropriate credit to the original author(s) and the source, provide a link to the Creative Commons licence, and indicate if changes were made. The images or other third party material in this article are included in the article's Creative Commons licence, unless indicated otherwise in a credit line to the material. If material is not included in the article's Creative Commons licence and your intended use is not permitted by statutory regulation or exceeds the permitted use, you will need to obtain permission directly from the copyright holder. To view a copy of this licence, visit http://creativecommons.org/licenses/by/4.0/ The Creative Commons Public Domain Dedication waiver (http://creativecommons.org/publicdomain/zero/1.0/) applies to the data made available in this article, unless otherwise stated in a credit line to the data. 


\section{Background}

Lung cancer is the leading cause of cancer-related death worldwide, and non-small-cell lung cancer (NSCLC) accounts for $80-85 \%$ of cases [1]. Among NSCLC, lung squamous cell carcinoma (SCC) is the second most common histology type, accounting for $20-30 \%$ of cases $[2,3]$. The treatment of lung adenocarcinoma has evolved considerably due to the emergence of specifically targeted therapies against identified molecular drivers, such as epidermal growth factor receptor (EGFR), anaplastic lymphoma kinase (ALK), c-ros oncogene 1 (ROS1), and murine sarcoma viral oncogene homolog $\mathrm{B}$ (BRAF). By contrast, advancements in the targeted treatment of SCC have remained limited due to high molecular heterogeneity $[4,5]$. Mutations are infrequently observed in the genes encoding members of the ErbB family of receptor tyrosine kinases, and targeted therapy is available for these cases [6]; however, the nature of mutations identified in lung SCC differs considerably from those identified in lung adenocarcinoma, resulting in sizable differences in treatment efficacy [7]. For advanced NSCLC patients with no targetable molecular drivers, platinum-based doublet chemotherapy has long been the standard first-line treatment, with good performance status, until the recent introduction of immunotherapy $[8,9]$.

In the recent past, immunotherapy targeting immune checkpoint proteins has been the most promising novel cancer treatment, and the introduction of immune checkpoint inhibitors (ICIs) into routine clinical practice has improved outcomes in patients with lung SCC. ICIs play a prominent role as first-line therapy, and common regimens include pembrolizumab plus carboplatin and paclitaxel/nab-paclitaxel, regardless of programmed death-ligand 1 (PD-L1) level [10, 11]; pembrolizumab monotherapy $[11,12]$ or nivolumab plus ipilimumab [13] in patients with a PD-L1 tumor proportion score (TPS) $\geq 1 \%$; and atezolizumab monotherapy or cemiplimab monotherapy in patients with high PD-L1 expression, [14, 15] all of which have provided promising survival benefits.

Although ICIs have altered the first-line treatment paradigms for patients with lung SCC, few treatment options are available for advanced SCC of the lung after the failure of first-line platinum-based doublet chemotherapy or immunotherapy-based treatment. Docetaxel is generally considered to be a standard second-line treatment when patients progress after treatment with platinum-based chemotherapy $[11,16]$, and the addition of ramucirumab to docetaxel may further improve survival but increase toxicity [17]. Other chemotherapy options including gemcitabine monotherapy or platinumbased chemotherapy (if not included as first-line treatment). The only approved chemotherapy-free targeted therapy for second-line treatment is the pan-human epidermal growth factor receptor (HER) family tyrosine kinase inhibitor (TKI), afatinib, which demonstrated significant improved progression-free survival (PFS; median 2.4 vs. 1.9 months) and overall survival (OS; median 7.9 vs. 6.8 months) during the LUX-Lung 8 trial [18]. However, the benefits of afatinib were established based on comparisons with erlotinib rather than relative to chemotherapy. Therefore, the use of afatinib for secondor third-line therapy is currently recognized by the European Society of Medical Oncology (ESMO) but is not recommended by the US National Comprehensive Cancer Network (NCCN) Clinical Practice Guidelines in Oncology. Clinical evidence regarding the efficacy of afatinib versus chemotherapy for relapsed lung SCC remains lacking. In this study, we aimed to explore the real-world efficacy and safety of afatinib compared with chemotherapy.

\section{Methods}

The present study was performed as a retrospective, observational, multicenter study. Our aim was to evaluate the treatment outcomes and safety of afatinib versus chemotherapy in patients with advanced SCC who progressed after first-line chemotherapy in a real-world setting. We retrospectively recruited patients with initial locally advanced or metastatic lung SCC from four tertiary referral hospitals in Taiwan who received secondline treatment initiation between June 2014 and October 2020. The inclusion criteria were as follows: (a) histologically confirmed as locally advanced or metastatic SCC; and (b) disease recurrence after first-line chemotherapy, without prior immunotherapy exposure. Patients who were treated with other epidermal growth factor receptor (EGFR)-TKIs were not included. Data were extracted from patient's electronic medical records and included demographic and clinical characteristics comprising sex, age, comorbidities, Eastern Cooperative Oncology Group performance status (ECOG PS), initial cancer stage, metastatic sites, first- and second-line treatment, and clinical response.

All the patients included for analysis in the study composed the original cohort, and a propensity-score (PS) approach with 1:1 matching with caliper width of 0.2 was applied to the original cohort to build a propensityscore matching (PSM) cohort. Propensity scores was created through logistic regression as a function of age, sex, first-line chemotherapy, initial clinical stage, baseline ECOG PS, brain metastasis at baseline. We conducted outcome analysis based on second-line treatment for both original cohort and PSM cohort.

The primary endpoint of this study was PFS on second-line treatment, defined as the time from the start of second-line treatment to the time of treatment 
progression or death, whichever occurred first. The key secondary endpoint was OS, defined as the time from initial lung cancer diagnosis to the time of death. Other secondary endpoints included the objective response rate (ORR), disease control rate (DCR), and treatmentrelated adverse events (TRAEs). Categorical variables were presented as numbers with percentages and were compared using Fisher's exact test. Continuous variables were summarized as median with interquartile range (IQR), and compared using the Mann-Whitney $U$ test. Survival analysis was performed using the Kaplan-Meier method. The median and 2-sided 95\% confidence intervals (CIs) were determined, and significance was assessed using the log-rank test. Hazard ratios and corresponding 95\% CIs were estimated using a Cox proportional-hazards model. As this study involved human participants, all procedures were performed in accordance with the ethical standards of the Institutional and National Research Committee and the 1964 Declaration of Helsinki and its later amendments or comparable ethical standards. This study was subject to the supervision and management of the ethics committees of all participating institutes. Statistical analyses were performed using MedCalc Statistical Software version 19.5.3 (MedCalc Software bvba, Ostend, Belgium) and SPSS software version 25.0 (SPSS Inc., Armonk, NY).

\section{Results}

Overall, 108 patients were identified for inclusion during the study period and formed the original cohort: 19 received afatinib, and 89 received chemotherapy as second-line treatment (Table 1). The median age at initiation of second-line therapy was 71 years (interquartile range [IQR], 63-82 years) in the afatinib group and 67 years (IQR, 61-74 years) in the chemotherapy group. At initial diagnosis, most patients had stage IV disease (afatinib, 63.2\%; chemotherapy, 73\%), the percentage of current smokers was higher among patients who received afatinib than among those who received chemotherapy (68.4\% vs. $49.4 \%)$. The contralateral lung was the most common site of metastatic disease (36.8 and $28.1 \%$ in the afatinib and chemotherapy groups, respectively), while $6(31.6 \%)$ and $12(13.5 \%)$ patients in the afatinib and chemotherapy groups had brain metastases, respectively. Thirty-six percent of patients in the afatinib group were tested for EGFR mutation, compared to $43.8 \%$ of the patients in the chemotherapy group. The expression level of PD-L1 was comparable between two groups. A total of 19 patient pairs were PS matched from the original cohort (PSM cohort), the demographic and clinical characteristics were matched between group.

Among the chemotherapy group, $33.7 \%$ of patients received gemcitabine or gemcitabine-based therapy; $28.1 \%$ received vinorelbine or vinorelbine-based therapy; $28.1 \%$ received docetaxel or docetaxel-based therapy; $7.9 \%$ received other regimens; and $2.2 \%$ received atezolizumab monotherapy (Table 2). Median time on treatment for first-line chemotherapy was 6.0 months [95\% CI, 1.2-9.1 months] in the afatinib group and 5.4 months [95\% CI, $0.9-11.2$ months] in the chemotherapy group (Table 3).

After a median follow-up of 12.7 months (IQR, 10.116.0 months), PFS was significantly longer among patients who received afatinib than among those who received chemotherapy (median 4.7 months [95\% CI, 0.17.5 months] vs. 2.6 months [95\% CI, 0.9-6.7 months]; hazard ratio (HR) 0.53 [95\% CI, 0.32-0.88], $p=0.013$; Fig. 1A). More patients in the afatinib group than in the chemotherapy group had an objective response (ORR: $26.3 \%$ vs. $7.9 \%, p=0.020$ ), according to an independent review (Table 3). Disease control was also greater in the afatinib group than in the chemotherapy group (DCR: $84.2 \%$ vs. $46.1 \%, p=0.003$ ). OS was comparable between groups (median 16.0 months among afatinib group [95\% CI, 6.1-22.0 months] vs. 12.3 months among chemotherapy group [95\% CI, 6.2-33.9 months]; HR 0.65 [95\% CI, $0.38-1.11], p=0.112$; Fig. 1B). Pertaining to the PSM cohort, results of outcomes analysis were highly consistent with the original cohort. PFS was significantly longer in patients who received afatinib than those who received chemotherapy (median 4.7 months [95\% CI, 0.1-7.5 months] vs. 1.9 months [95\% CI, 0.4-8.4 months]; hazard ratio (HR) 0.51 [95\% CI, 0.26-0.98], $p=0.039$; Fig. $1 \mathrm{C}$ ). OS was comparable between groups (median 16.0 months among afatinib group [95\% CI, 6.1-22.0 months] vs. 9.9 months among chemotherapy group $[95 \% \mathrm{CI}$, 6.2-39.4 months]; HR 0.76 [95\% CI, 0.38-1.64], $p=$ 0.531; Fig. 1D). The ORR and DCR among patients treated with afatinib surpassed those of patients treated with chemotherapy (Table 3).

Beyond second-line treatment, twenty-three patients ( 3 patients in the afatinib group and 20 patients in the chemotherapy group) accepted further third-line treatment. All three patients from afatinib group received chemotherapy alone or in combination with antiangiogenesis agents. Among the chemotherapy group, thirteen patients received chemotherapy alone or in combination with anti-angiogenesis agents, three received immunochemotherapy, one received immunotherapy alone and the other three received EGFR-TKI as third-line treatment (supplementary Table 1).

When examining TRAEs, $89.5 \%$ of patients in the afatinib group versus $73.0 \%$ in the chemotherapy group reported any grade of adverse effects. The majority of patients $(89.5 \%)$ in the afatinib group experienced skin (paronychia, rashes, or acne) and gastrointestinal (nausea, vomiting, or diarrhea) toxicities; less frequent events included mucositis (21.1\%) and laboratory-confirmed 
Table 1 Baseline Demographic and Clinical Characteristics

\begin{tabular}{|c|c|c|c|c|c|c|}
\hline \multirow[b]{2}{*}{ Second-Line Treatment } & \multicolumn{3}{|c|}{ Original cohort } & \multicolumn{3}{|c|}{ Propensity-score matching cohort } \\
\hline & $\begin{array}{l}\text { Afatinib } \\
(n=19)\end{array}$ & $\begin{array}{l}\text { Chemotherapy } \\
(n=89)\end{array}$ & $p$-value & $\begin{array}{l}\text { Afatinib } \\
(n=19)\end{array}$ & $\begin{array}{l}\text { Chemotherapy } \\
(n=19)\end{array}$ & $p$-value \\
\hline Age, y (IQR) & $71(63-82)$ & $67(61-74)$ & 0.107 & $71(63-82)$ & $66(60-74)$ & 0.144 \\
\hline Male, n (\%) & $14(73.7)$ & $73(82.0)$ & 0.404 & $14(73.7)$ & $16(84.2)$ & 0.426 \\
\hline Smoking status, n (\%) & & & 0.875 & & & 0.721 \\
\hline Never smoker & $5(26.3)$ & $25(28.1)$ & & $5(26.3)$ & $6(31.6)$ & \\
\hline Ex-smoker & $1(5.3)$ & $21(23.6)$ & & $1(5.3)$ & $3(15.8)$ & \\
\hline Current smoker & $13(68.4)$ & $44(49.4)$ & & $13(68.4)$ & $10(52.6)$ & \\
\hline First-line chemotherapy, n (\%) & & & 0.118 & & & 0.174 \\
\hline Platinum-based & $11(57.9)$ & $71(79.8)$ & & $11(57.9)$ & $15(78.9)$ & \\
\hline Not platinum-based & $8(42.1)$ & $18(20.2)$ & & $8(42.1)$ & $4(21.1)$ & \\
\hline Initial clinical stage, n (\%) & & & 0.331 & & & 0.283 \\
\hline$\| \mathrm{B} / \mathrm{C}$ & $7(36.8)$ & $24(27.0)$ & & $7(36.8)$ & $4(21.1)$ & \\
\hline IV & $12(63.2)$ & $65(73.0)$ & & $12(63.2)$ & $15(78.9)$ & \\
\hline Baseline ECOG PS & & & 0.135 & & & 0.221 \\
\hline $0 / 1$ & $12(63.2)$ & $76(85.4)$ & & $12(63.2)$ & $16(84.2)$ & \\
\hline$\geq 2$ & $7(36.8)$ & $13(14.6)$ & & $7(36.8)$ & $3(15.8)$ & \\
\hline EGFR status, n (\%) & & & 0.577 & & & 0.560 \\
\hline Wild-type & $7(36.8)$ & $39(43.8)$ & & $7(36.8)$ & $5(26.3)$ & \\
\hline Not tested & $12(63.2)$ & $50(56.2)$ & & $12(63.2)$ & $14(73.7)$ & \\
\hline PD-L1 expression level, n (\%) & & & 0.278 & & & 0.530 \\
\hline$<1 \%$ & $5(26.3)$ & $13(14.6)$ & & $5(26.3)$ & $2(10.5)$ & \\
\hline $1-49 \%$ & $2(10.5)$ & $27(30.3)$ & & $2(10.5)$ & $3(15.8)$ & \\
\hline$>50 \%$ & $2(10.5)$ & $10(11.2)$ & & $2(10.5)$ & $1(5.3)$ & \\
\hline Not tested & $10(52.6)$ & $39(43.8)$ & & $10(52.6)$ & $13(68.4)$ & \\
\hline \multicolumn{7}{|l|}{ Sites of metastatic disease, $\mathrm{n}(\%)$} \\
\hline Liver & $0(0)$ & $10(11.2)$ & 0.125 & $0(0)$ & $1(5.3)$ & 0.311 \\
\hline Contralateral lung nodule & $7(36.8)$ & $25(28.1)$ & 0.448 & $7(36.8)$ & $3(15.8)$ & 0.141 \\
\hline Bone & $3(15.8)$ & $25(28.1)$ & 0.267 & $3(15.8)$ & $5(26.3)$ & 0.426 \\
\hline Pleural (nodules, effusion) & $2(10.5)$ & $15(16.9)$ & 0.641 & $2(10.5)$ & $5(26.3)$ & 0.209 \\
\hline Brain & $6(31.6)$ & $12(13.5)$ & 0.055 & $6(31.6)$ & $4(21.1)$ & 0.521 \\
\hline Other & $0(0)$ & $7(7.9)$ & 0.718 & $0(0)$ & $3(15.8)$ & 0.107 \\
\hline \multicolumn{7}{|l|}{ Comorbidity, n (\%) } \\
\hline Hypertension & $4(21.1)$ & $42(47.2)$ & 0.054 & $4(21.1)$ & $9(47.4)$ & 0.087 \\
\hline Chronic kidney disease & $0(0)$ & $3(3.4)$ & 0.417 & $0(0)$ & $1(5.3)$ & 0.311 \\
\hline Diabetes mellitus & $4(21.1)$ & $22(24.7)$ & 0.734 & $4(21.1)$ & $5(26.3)$ & 0.703 \\
\hline Hepatic disease & $0(0)$ & $9(10.1)$ & 0.148 & $0(0)$ & $2(10.5)$ & 0.214 \\
\hline Pulmonary disease & $4(21.1)$ & $25(28.1)$ & 0.734 & $4(21.1)$ & $2(10.5)$ & 0.374 \\
\hline
\end{tabular}

IQR interquartile range; ECOG PS Eastern Cooperative Oncology Group performance status; EGFR epidermal growth factor receptor; PD-L1 programmed cell death protein 1

hematologic toxicity $(5.3 \%$ presented with neutropenia, anemia, or thrombocytopenia, which developed after treatment initiation). By contrast, hematologic toxicity and neuropathy were more prominent in the chemotherapy group (68.5 and 16.9\%, respectively); skin and gastrointestinal toxicities were less commonly reported among patients who received chemotherapy (Table 4). 
Table 2 Second-Line Treatment Regimens in the Chemotherapy Group $(n=89)$

\begin{tabular}{ll}
\hline Second-Line Therapy Received, $\mathbf{n}(\%)$ & \\
\hline Gemcitabine & $28(31.5)$ \\
Vinorelbine & $24(26.9)$ \\
Docetaxel & $22(24.7)$ \\
Others & $7(7.9)$ \\
Carboplatin/gemcitabine & $2(2.2)$ \\
Atezolizumab & $2(2.2)$ \\
Carboplatin/docetaxel & $2(2.2)$ \\
Carboplatin/vinorelbine & $1(1.1)$ \\
Pembrolizumab/docetaxel & $1(1.1)$ \\
\hline
\end{tabular}

\section{Discussion}

The results of this study provide insights regarding the efficacy and safety of second-line afatinib for the treatment of patients with lung SCC following disease progression after first-line chemotherapy. In the present study, the median PFS with second-line afatinib (4.7 months) was significantly longer than that with secondline chemotherapy ( 2.6 months). Although the OS was longer in the afatinib group (16.0 months) than in the chemotherapy group (12.3 months), this difference did not reach significance. The PSM cohort carried the consistent consequence, improved the convincing power and indicated our findings were robust. Our results implied that afatinib represents an optimal treatment choice following chemotherapy in patients with lung SCC following progression after first-line treatment in a real-world setting.

The introduction of ICIs for the treatment of advanced lung SCC represents a breakthrough associated with improved outcomes over the past decade. First-line ICI monotherapy or ICI combination therapy is supported by several large Phase III studies, which have demonstrated remarkably extended survival [13, 14, 19, 20]. Notably, combined immunochemotherapy also provided longer PFS and probable longer OS than chemotherapy alone in patients with metastatic SCC NSCLC, regardless of PD-L1 level [10, 21]. ICIs have practically replaced docetaxel as the second-line treatment for advanced NSCLC, several ICIs demonstrated significantly longer OS than docetaxel, regarding to different PD-L1 expression level [22-29]. However, ICIs are not always available or affordable in certain countries, including Taiwan; therefore, we did not include patients treated with ICIs in this study (ICI-naïve patients only). In addition, among patients who present with contraindications to immunotherapy, such as autoimmune diseases or previous solid organ transplant, combination cytotoxic chemotherapy or alternative afatinib (for patients unfit for chemotherapy) is recommended [30, 31]. We suggest that afatinib represents a second-line alternative treatment option for immunotherapy unfit advanced lung SCC patients.

The role of EGFR-TKIs in the treatment of lung SCC without EGFR-activating mutations has been evaluated in several clinical trials. The BR.21 trial, a multicentric, randomized, Phase III trial, reported a median PFS of 2.2 months in the erlotinib group versus 1.8 months in the placebo supportive care group (HR, 0.61, $p<0.001$ ) [32]. By contrast, the TAILOR and DELTA trials further compared erlotinib against the standard second-line chemotherapy treatment with docetaxel in pretreated patients with advanced NSCLC unselected for EGFR mutation. The OS and PFS among patients treated with docetaxel surpassed those of patients treated with erlotinib, which was especially evident in the subgroup with

Table 3 Best Overall Tumor Response to Second-Line Treatment

\begin{tabular}{|c|c|c|c|c|c|c|}
\hline & Original cohor & & & Propensity-sco & matching cohor & \\
\hline & $\begin{array}{l}\text { Afatinib } \\
(n=19)\end{array}$ & $\begin{array}{l}\text { Chemotherapy } \\
(n=89)\end{array}$ & $p$-value & $\begin{array}{l}\text { Afatinib } \\
(n=19)\end{array}$ & $\begin{array}{l}\text { Chemotherapy } \\
(n=19)\end{array}$ & $p$-value \\
\hline Disease control, n (\%) & $16(84.2)$ & $41(46.1)$ & $0.003^{*}$ & $16(84.2)$ & $8(42.1)$ & $0.007^{*}$ \\
\hline Objective response, n (\%) & $5(26.3)$ & $7(7.9)$ & $0.020^{*}$ & $5(26.3)$ & $2(10.5)$ & $0.209^{*}$ \\
\hline CR, n (\%) & $0(0)$ & $0(0)$ &. & $0(0)$ & $0(0)$ &. \\
\hline PR, n (\%) & $5(26.3)$ & $7(7.9)$ &. & $5(26.3)$ & $2(10.5)$ &. \\
\hline SD, n (\%) & $11(57.9)$ & $34(38.2)$ &. & $11(57.9)$ & $6(31.6)$ &. \\
\hline PD, n (\%) & $2(10.5)$ & $43(48.3)$ &. & $2(10.5)$ & $7(36.8)$ &. \\
\hline$N E, n(\%)$ & $1(5.3)$ & $5(5.6)$ &.. & $1(5.3)$ & $2(10.5)$ &. \\
\hline Time on first-line treatment, months (95\% Cl) & $6(1.2-9.1)$ & $5.4(0.9-11.2)$ &. & $6(1.2-9.1)$ & $3.5(0.4-13.9)$ &. \\
\hline PFS, months (95\% Cl) & $4.7(0.1-7.5)$ & $2.6(0.9-6.7)$ &.. & $4.7(0.1-7.5)$ & $1.9(0.4-8.4)$ &. \\
\hline OS, months (95\% Cl) & $16.0(6.1-22.0)$ & $12.3(6.2-33.9)$ &.. & $16.0(6.1-22.0)$ & $9.9(6.2-39.4)$ &.. \\
\hline
\end{tabular}

$C R$ complete response; $P R$ partial response; $S D$ stable disease; $P R$ progressive disease; NE not evaluable; $P F S$ progression-free survival of second-line treatment; OS overall survival

${ }^{*}$ Categorical variables were compared using the Fisher's exact test 


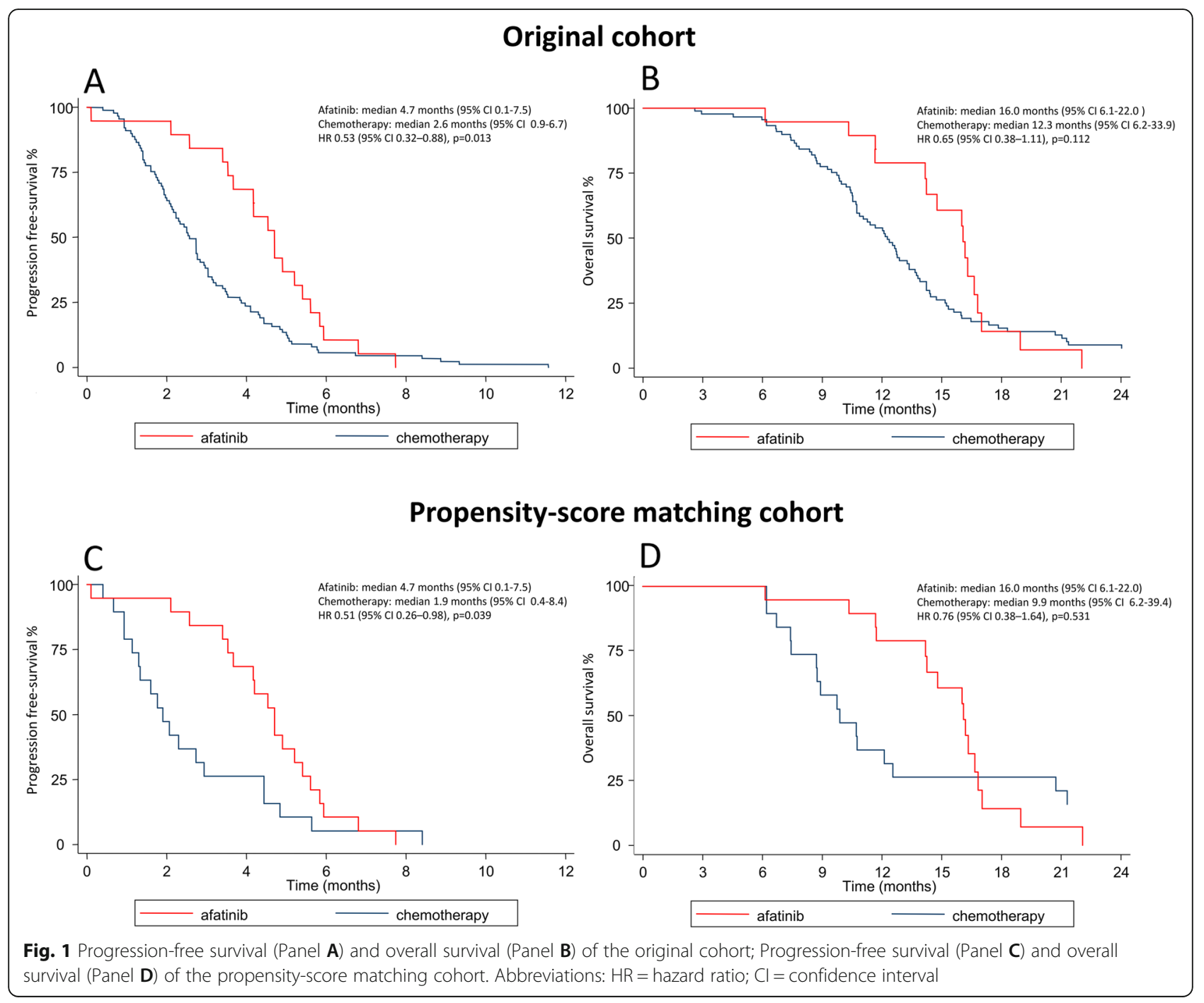

SCC histology [33, 34]. Therefore, the FDA restricted erlotinib second-line indications to patients with EGFR del 19 or L858R mutations in 2016 [35]. The therapeutic role of afatinib was established by the LUX-Lung 8 study, a large, multi-national, Phase III trial specifically designed for a population in which EGFR mutations are almost absent. The study reported an advantage for both the primary endpoint of PFS (0.5 months) and the secondary endpoints of OS (1.1 months), DCR, and symptom control. Although EGFR-TKIs showed better tolerability and comparable OS as second-line therapy compared with chemotherapy in a meta-analysis [36], the results were primarily due to the comparison between erlotinib and chemotherapy. The direct

Table 4 Any Grade of Treatment-Related Adverse Events (TRAEs)

\begin{tabular}{|c|c|c|c|}
\hline & $\begin{array}{l}\text { Afatinib } \\
(n=19)\end{array}$ & $\begin{array}{l}\text { Chemotherapy } \\
(n=89)\end{array}$ & $p$-value \\
\hline TRAEs & $17(89.5)$ & $65(73.0)$ & 0.128 \\
\hline Skin toxicity (paronychia, rash, acne), n (\%) & $17(89.5)$ & $5(5.6)$ & $<0.001$ \\
\hline Gastrointestinal toxicity (nausea, vomiting, diarrhea), n (\%) & $17(89.5)$ & $10(11.2)$ & $<0.001$ \\
\hline Mucositis, n (\%) & $4(21.1)$ & $10(11.2)$ & 0.248 \\
\hline Abnormal liver function, $\mathrm{n}(\%)$ & $0(0)$ & $7(7.9)$ & 0.206 \\
\hline Hematologic toxicity (neutropenia, anemia, thrombocytopenia), n (\%) & $1(5.3)$ & $61(68.5)$ & $<0.001$ \\
\hline Neuropathy, n (\%) & $0(0)$ & 15 (16.9) & 0.156 \\
\hline
\end{tabular}


comparison between afatinib and chemotherapy for second-line treatment was lacking. To the best of our knowledge, this retrospective study provides the first available insights into the real-world use of afatinib compared with chemotherapy following the failure of firstline chemotherapy in patients with lung SCC.

The Phase III trial REVEL compared the combination of docetaxel plus ramucirumab against docetaxel alone in patients with SCC and non-SCC NSCLC who previously received platinum-based treatment, which revealed significant improvement in PFS (4.5 vs. 3.0 months; HR, $0.76, p<0.0001)$ and OS (10.5 vs. 9.1 months; HR, 0.86, $p=0.02)$ for the combination group. No patients in our study received vascular endothelial growth factor receptor (VEGFR) monoclonal antibodies in combination with docetaxel, which may lower the treatment effect in the chemotherapy group. However, among patients 65 years or older, the additional benefits of ramucirumab were not as evident as among younger patients, and extra toxicity may occur $[37,38]$. The patients in our study were older than those included in previous major clinical trials; thus, the benefits and tolerance for combination treatment should be considered thoroughly according to the patients' physiological condition. Most patients in the present study encountered manageable skin and gastrointestinal toxicities; laboratory-confirmed hematologic toxicity or neuropathy occurred less frequently in afatinib-treated patients compared with chemotherapy-treated patients. Differences in the presentation of adverse effects implied that second-line afatinib treatment for lung SCC offered better tolerability and quality of life than chemotherapy, which may lead to longer survival.

Previously approved agents have been subsequently moved more marginally in the therapeutic algorithm for SCC because of the approval of ICIs as first- and second-line treatments. However, EGFR-TKIs represent an available therapeutic option for lung SCC following the failure of previous lines of treatment, and EGFRTKIs are easily managed as an oral drug with good tolerability compared with chemotherapy [39, 40]. Moreover, an applicable percentage of patients gained modest improvement in symptom control and quality of life from afatinib use [41]. Among patients who are not suitable candidates for cytotoxic chemotherapy or immunotherapy, afatinib may represent a convenient second- or third-line treatment option. Afatinib has been proved to be a good immuno-modulator which might modify the microenvironment of tumors, upregulate the PD-L1 expression, and possibly improved the immunotherapy effect [42, 43]. Further investigation of the crosstalk between the EGFR and PD-L1 pathways may be a rational approach to improve lung squamous cell carcinoma treatment [44]. Sequential or Combined immunotherapy with various of EGFR-TKI did show some encouraging antitumor activity but the safety profiles were highly varied [45-47]. Studies of second-line or third-line afatinib after chemotherapy or immunotherapy is ongoing currently. Only a minority of the patients received third-line treatment in this study, which didn't aim to answer the complexities of the crosstalk between these pathophysiology pathways; nevertheless, we presented a convincing result that second-line afatinib may be considered as alternative treatment choice for first-line immunotherapy unfit advanced lung SCC patients.

This study has several limitations. First, due to the retrospective nature of the study, the data for some patients might be influenced by incomplete records and uneven patient characteristics. Patients with good ECOG PS were more likely to receive first-line platinum-based chemotherapy, and younger patients represented a higher proportion of the chemotherapy group. By contrast, afatinib was more commonly administered for patients with poor PS and among older individuals, complementing the PFS and OS benefits of afatinib. Second, this study recruited patients from only four institutes, and the limited provider and patient source may result in a highly selected patient population. Although we conducted a multi-institute study, the number of patients who received second-line afatinib treatment was small, reflecting the dramatic decrease in the frequency of using targeted therapy as second-line treatment during the immunotherapy era. PS matching analysis was used to eliminate of potential confounding, which indicated that our findings were robust and increased the convincing power of the study. Therefore, the results of our study were commendable and may offer a reference for a clinical setting in which immunotherapy is not universally available. Third, detailed subgroup analysis was difficult to be executed owing to the limited sample size. In order to avoid false positives due to multiple comparisons, this study didn't report subgroup analysis to identify which specific patient group might benefit most from afatinib. Finally, the majority of the patient did not receive EGFR mutation test and further genomic studies, specific information regarding driver oncogenes detection was not available, and the underlying biology and the nature of progression in individual patients might have influenced the treatment effect. Further large-scale prospective studies are warranted to validate these findings.

\section{Conclusions}

Afatinib offered longer PFS and comparable OS to chemotherapy in patients with lung SCC progression after first-line chemotherapy in a real-world setting. At present, afatinib is the only approved oral agent 
following chemotherapy in patients with lung SCC, and physicians are encouraged to consider it as a second-line alternative treatment choice for immunotherapy unfit advanced lung SCC patients.

\begin{abstract}
Abbreviations
NSCLC: Non-small-cell lung cancer; SCC: Squamous cell carcinoma;

EGFR: Epidermal growth factor receptor; ALK: Anaplastic lymphoma kinase;

ROS1: C-ros oncogene 1; BRAF: Murine sarcoma viral oncogene homolog B;

ICls: Immune checkpoint inhibitors; PD-L1: Programmed death-ligand 1;

TPS: Tumor proportion score; PFS: Progression-free survival; OS: Overall survival; ESMO : European Society of Medical Oncology; EGFR-TKI: EGFRtyrosine kinase inhibitor.; ECOG PS : Eastern Cooperative Oncology Group performance status; ORR: Objective response rate; DCR: Disease control rate; HR: Hazard ratio.; TRAEs : Treatment-related adverse events; VEGFR: Vascular endothelial growth factor receptor.
\end{abstract}

\section{Supplementary Information}

The online version contains supplementary material available at https://doi. org/10.1186/s12885-021-08920-3.

Additional file 1: Supplementary Table 1. 3rd Line Treatment

Regimens $(n=23)$.

\section{Acknowledgements}

Not Applicable.

\section{Authors' contributions}

YYC and CYC takes responsibility for the contents of this manuscript, including the data and analysis. SCC, CYC, YFW, and CYC contributed to the study concept and design; SCC, CYC, YFW, CFC, YCL, and CYC contributed to data collection and analysis; YYC drafted the manuscript; SCC, CYC, YFW, and CYC contributed to the critical appraisal of this manuscript. SCC, CYC, and YFW contributed equally to this work. All authors approved the submission of this version for publication.

\section{Funding}

No funding was obtained for this study.

\section{Availability of data and materials}

The datasets used and/or analyzed during the current study are available from the corresponding author on reasonable request.

\section{Declarations}

\section{Ethics approval and consent to participate}

The Institutional Review Board of the National Taiwan University Hospital (IRB number:201611059RING) approved this study, and waived the informed consent requirement given the retrospective nature of this study and the lack of patient safety concerns. All experiments were performed in accordance with relevant guidelines and regulations (Declaration of Helsinki).

\section{Consent for publication}

Not applicable.

\section{Competing interests}

The authors declare that they have no competing interests.

\section{Author details}

'Division of Pulmonary and Critical Care Medicine, Department of Internal Medicine, National Taiwan University Hospital Yunlin Branch, Yunlin Count, Douliu City, Taiwan, Republic of China. ${ }^{2}$ College of Medicine, National Taiwan University, Taipei, Taiwan. ${ }^{3}$ Division of Chest Medicine, Department of Internal Medicine, National Yang Ming Chiao Tung University Hospital, Yilan County, Taiwan. ${ }^{4}$ Division of Pulmonary Medicine, Department of Internal Medicine, Far Eastern Memorial Hospital, and Department of Nursing, Cardinal Tien College of Healthcare and Management, New Taipei City, Taiwan. ${ }^{5}$ Department of Internal Medicine, E-Da Cancer Hospital, Kaohsiung,
Taiwan. ${ }^{6}$ School of Medicine for International Students, College of Medicine, and Institute of Biotechnology and Chemical Engineering, I-Shou University, Kaohsiung, Taiwan.

Received: 18 July 2021 Accepted: 25 October 2021

Published online: 15 November 2021

\section{References}

1. Torre LA, Siegel RL, Ward EM, Jemal A. Global Cancer incidence and mortality rates and trends--an update. Cancer Epidemiol Biomark Prev. 2016 25(1):16-27. https://doi.org/10.1158/1055-9965.EPI-15-0578.

2. Travis WD. Pathology of lung cancer. Clin Chest Med. 2011;32(4):669-92. https://doi.org/10.1016/j.ccm.2011.08.005.

3. Fan Z, Schraeder R. The changing pathology of lung cancer. Surg Oncol Clin N Am. 2011;20(4):637-53. https://doi.org/10.1016/j.soc.2011.07.004.

4. Jamal-Hanjani M, Spicer J. Epidermal growth factor receptor tyrosine kinase inhibitors in the treatment of epidermal growth factor receptor-mutant non-small cell lung cancer metastatic to the brain. Clin Cancer Res. 2012; 18(4):938-44. https://doi.org/10.1158/1078-0432.CCR-11-2529.

5. Petrelli F, Borgonovo K, Cabiddu M, Barni S. Efficacy of EGFR tyrosine kinase inhibitors in patients with EGFR-mutated non-small-cell lung cancer: a meta-analysis of 13 randomized trials. Clin Lung Cancer. 2012;13(2):107-14. https://doi.org/10.1016/j.cllc.2011.08.005

6. Cancer Genome Atlas Research N. Comprehensive genomic characterization of squamous cell lung cancers. Nature. 2012;489(7417):519-25. https://doi. org/10.1038/nature11404.

7. Liao BC, Lin CC, Yang JC. Novel EGFR inhibitors in non-small cell lung Cancer: current status of Afatinib. Curr Oncol Rep. 2017;19(1):4. https://doi. org/10.1007/s11912-017-0560-2.

8. Magunia H, Haeberle HA, Henn P, Mehrlander M, Vlatten PO, Mirakaj V, et al. Early driving pressure changes predict outcomes during Venovenous extracorporeal membrane oxygenation for acute respiratory distress syndrome. Crit Care Res Pract. 2020;2020:6958152-9. https://doi.org/10.11 55/2020/6958152

9. Yang CY, Yang JC, Yang PC. Precision Management of Advanced non-Small Cell Lung Cancer. Annu Rev Med. 2020;71(1):117-36. https://doi.org/10.114 6/annurev-med-051718-013524.

10. Paz-Ares L, Luft A, Vicente D, Tafreshi A, Gumus M, Mazieres J, et al. Pembrolizumab plus chemotherapy for squamous non-small-cell lung Cancer. N Engl J Med. 2018;379(21):2040-51. https://doi.org/10.1056/ NEJMoa1810865.

11. Paz-Ares L, Vicente D, Tafreshi A, Robinson A, Soto Parra H, Mazieres J, et al. A randomized, placebo-controlled trial of Pembrolizumab plus chemotherapy in patients with metastatic squamous NSCLC: protocolspecified final analysis of KEYNOTE-407. J Thorac Oncol. 2020;15(10):165769. https://doi.org/10.1016/j.jtho.2020.06.015.

12. Wu YL, Zhang L, Fan Y, Zhou J, Zhang L, Zhou Q, et al. Randomized clinical trial of pembrolizumab vs chemotherapy for previously untreated Chinese patients with PD-L1-positive locally advanced or metastatic non-small-cell lung cancer: KEYNOTE-042 China study. Int J Cancer. 2021;148(9):2313-20. https://doi.org/10.1002/ijc.33399.

13. Hellmann MD, Paz-Ares L, Bernabe Caro R, Zurawski B, Kim SW, Carcereny Costa $E$, et al. Nivolumab plus Ipilimumab in advanced non-small-cell lung Cancer. N Engl J Med. 2019:381(21):2020-31. https://doi.org/10.1056/ NEJMoa1910231.

14. Herbst RS, Giaccone G, de Marinis F, Reinmuth N, Vergnenegre A, Barrios $\mathrm{CH}$, et al. Atezolizumab for first-line treatment of PD-L1-selected patients with NSCLC. N Engl J Med. 2020;383(14):1328-39. https://doi.org/10.1056/ NEJMoa1917346.

15. Sezer A, Kilickap S, Gumus M, Bondarenko I, Ozguroglu M, Gogishvili M, et al. Cemiplimab monotherapy for first-line treatment of advanced nonsmall-cell lung cancer with PD-L1 of at least 50\%: a multicentre, open-label, global, phase 3, randomised, controlled trial. Lancet. 2021;397(10274):592604. https://doi.org/10.1016/S0140-6736(21)00228-2.

16. Fossella FV, DeVore R, Kerr RN, Crawford J, Natale RR, Dunphy F, et al. Randomized phase III trial of docetaxel versus vinorelbine or ifosfamide in patients with advanced non-small-cell lung cancer previously treated with platinum-containing chemotherapy regimens. The TAX 320 non-small cell lung Cancer study group. J Clin Oncol. 2000;18(12):2354-62. https://doi. org/10.1200/JCO.2000.18.12.2354. 
17. Garon EB, Ciuleanu TE, Arrieta O, Prabhash K, Syrigos KN, Goksel T, et al. Ramucirumab plus docetaxel versus placebo plus docetaxel for second-line treatment of stage IV non-small-cell lung cancer after disease progression on platinum-based therapy (REVEL): a multicentre, double-blind, randomised phase 3 trial. Lancet. 2014;384(9944):665-73. https://doi.org/10.1 016/S0140-6736(14)60845-X.

18. Goss GD, Cobo M, Lu S, Syrigos K, Lee KH, Goker E, et al. Afatinib versus erlotinib as second-line treatment of patients with advanced squamous cell carcinoma of the lung: final analysis of the randomised phase 3 LUX-lung 8 trial. EClinicalMedicine. 2021;37:100940. https://doi.org/10.1016/j.eclinm.2 021.100940 .

19. Nosaki K, Saka H, Hosomi Y, Baas P, de Castro G Jr, Reck M, et al. Safety and efficacy of pembrolizumab monotherapy in elderly patients with PD-L1positive advanced non-small-cell lung cancer: pooled analysis from the KEYNOTE-010, KEYNOTE-024, and KEYNOTE-042 studies. Lung Cancer. 2019; 135:188-95. https://doi.org/10.1016/j.lungcan.2019.07.004.

20. Mok TSK, Wu YL, Kudaba I, Kowalski DM, Cho BC, Turna HZ, et al. Pembrolizumab versus chemotherapy for previously untreated, PD-L1expressing, locally advanced or metastatic non-small-cell lung cancer (KEYNOTE-042): a randomised, open-label, controlled, phase 3 trial. Lancet. 2019;393(10183):1819-30. https://doi.org/10.1016/S0140-6736(18)32409-7.

21. Jotte R, Cappuzzo F, Vynnychenko I, Stroyakovskiy D, Rodriguez-Abreu D, Hussein $M$, et al. Atezolizumab in combination with carboplatin and nabpaclitaxel in advanced squamous NSCLC (IMpower131): results from a randomized phase III trial. J Thorac Oncol. 2020;15(8):1351-60. https://doi. org/10.1016/j.jtho.2020.03.028.

22. Mazieres J, Rittmeyer A, Gadgeel S, Hida T, Gandara DR, Cortinovis DL, et al. Atezolizumab versus docetaxel in pretreated patients with NSCLC: final results from the randomized phase 2 POPLAR and phase 3 OAK clinical trials. J Thorac Oncol. 2021;16(1):140-50. https://doi.org/10.1016/j.jtho.2020.09.022.

23. von Pawel J, Bordoni R, Satouchi M, Fehrenbacher L, Cobo M, Han JY, et al. Long-term survival in patients with advanced non-small-cell lung cancer treated with atezolizumab versus docetaxel: results from the randomised phase III OAK study. Eur J Cancer. 2019;107:124-32. https://doi.org/10.1016/j. ejca.2018.11.020

24. Fehrenbacher L, von Pawel J, Park K, Rittmeyer A, Gandara DR, Ponce Aix S, et al. Updated efficacy analysis including secondary population results for OAK: a randomized phase III study of Atezolizumab versus docetaxel in patients with previously treated advanced non-small cell lung Cancer. J Thorac Oncol. 2018;13(8):1156-70. https://doi.org/10.1016/j.jtho.2018.04.039.

25. Wu YL, Lu S, Cheng Y, Zhou C, Wang J, Mok T, et al. Nivolumab versus docetaxel in a predominantly Chinese patient population with previously treated advanced NSCLC: CheckMate 078 randomized phase III clinical trial. J Thorac Oncol. 2019;14(5):867-75. https://doi.org/10.1016/j.jtho.2019.01.006.

26. Horn L, Spigel DR, Vokes EE, Holgado E, Ready N, Steins M, et al. Nivolumab versus docetaxel in previously treated patients with advanced non-small-cell lung Cancer: two-year outcomes from two randomized, open-label, phase III trials (CheckMate 017 and CheckMate 057). J Clin Oncol. 2017;35(35):392433. https://doi.org/10.1200/JCO.2017.74.3062.

27. Brahmer J, Reckamp KL, Baas P, Crino L, Eberhardt WE, Poddubskaya E, et al. Nivolumab versus docetaxel in advanced squamous-cell non-small-cell lung Cancer. N Engl J Med. 2015;373(2):123-35. https://doi.org/10.1056/NEJMoa1 504627.

28. Herbst RS, Garon EB, Kim DW, Cho BC, Gervais R, Perez-Gracia JL, et al. 5year survival update from KEYNOTE-010: Pembrolizumab versus docetaxel for previously treated, programmed death ligand 1-positive advanced nonsmall-cell lung Cancer. J Thorac Oncol. 2021;16(10):1718-32. https://doi. org/10.1016/j.jtho.2021.05.001.

29. Herbst RS, Baas P, Kim DW, Felip E, Perez-Gracia JL, Han JY, et al. Pembrolizumab versus docetaxel for previously treated, PD-L1-positive, advanced non-small-cell lung cancer (KEYNOTE-010): a randomised controlled trial. Lancet. 2016;387(10027):1540-50. https://doi.org/10.1016/ S0140-6736(15)01281-7.

30. Park K, Vansteenkiste J, Lee KH, Pentheroudakis G, Zhou C, Prabhash K, et al. Pan-Asian adapted ESMO clinical practice guidelines for the management of patients with locally-advanced unresectable non-small-cell lung cancer: a KSMO-ESMO initiative endorsed by CSCO, ISMPO, JSMO, MOS, SSO and TOS. Ann Oncol. 2020;31(2):191-201. https://doi.org/10.1016/j.annonc.2019.10.026.

31. Wu YL, Planchard D, Lu S, Sun H, Yamamoto N, Kim DW, et al. Pan-Asian adapted clinical practice guidelines for the management of patients with metastatic non-small-cell lung cancer: a CSCO-ESMO initiative endorsed by
JSMO, KSMO, MOS, SSO and TOS. Ann Oncol. 2019;30(2):171-210. https:// doi.org/10.1093/annonc/mdy554.

32. Shepherd FA, Rodrigues Pereira J, Ciuleanu T, Tan EH, Hirsh V, Thongprasert $\mathrm{S}$, et al. Erlotinib in previously treated non-small-cell lung cancer. N Engl J Med. 2005;353(2):123-32. https://doi.org/10.1056/NEJMoa050753.

33. Kawaguchi T, Ando M, Asami $K$, Okano $Y$, Fukuda M, Nakagawa $H$, et al. Randomized phase III trial of erlotinib versus docetaxel as second- or thirdline therapy in patients with advanced non-small-cell lung cancer: docetaxel and Erlotinib lung Cancer trial (DELTA). J Clin Oncol. 2014;32(18):1902-8. https://doi.org/10.1200/JCO.2013.52.4694.

34. Garassino MC, Martelli O, Broggini M, Farina G, Veronese S, Rulli E, et al. Erlotinib versus docetaxel as second-line treatment of patients with advanced non-small-cell lung cancer and wild-type EGFR tumours (TAILOR): a randomised controlled trial. Lancet Oncol. 2013;14(10):981-8. https://doi. org/10.1016/S1470-2045(13)70310-3.

35. U.S. Food and Drug Administration: Erlotinib (Tarceva). October 21, 2016.

36. Li N, Yang L, Ou W, Zhang L, Zhang SL, Wang SY. Meta-analysis of EGFR tyrosine kinase inhibitors compared with chemotherapy as second-line treatment in pretreated advanced non-small cell lung cancer. PLoS One. 2014;9(7):e102777. https://doi.org/10.1371/journal.pone.0102777.

37. Sakaguchi T, Furuya N, Ito K, Hida N, Morikawa K, Komase Y, et al. The efficacy and safety of ramucirumab plus docetaxel in older patients with advanced non-small cell lung cancer. Thorac Cancer. 2020;11(6):1559-65. https://doi.org/10.1111/1759-7714.13429.

38. Ramalingam SS, Perol M, Reck M, Kowalyszyn RD, Gautschi O, Kimmich M, et al. Efficacy and safety of Ramucirumab with docetaxel versus placebo with docetaxel as second-line treatment of advanced non-small-cell lung Cancer: a subgroup analysis according to patient age in the REVEL trial. Clin Lung Cancer. 2018;19(3):270-9 e273. https://doi.org/10.1016/j.cllc.2017.12.011.

39. Ciuleanu T, Stelmakh L, Cicenas S, Miliauskas S, Grigorescu AC, Hillenbach C, et al. Efficacy and safety of erlotinib versus chemotherapy in second-line treatment of patients with advanced, non-small-cell lung cancer with poor prognosis (TITAN): a randomised multicentre, open-label, phase 3 study. Lancet Oncol. 2012;13(3):300-8. https://doi.org/10.1016/S1470-2045(11)70385-0.

40. Hirsch FR, Herbst RS, Gandara DR. EGFR tyrosine kinase inhibitors in squamous cell lung cancer. Lancet Oncol. 2015;16(8):872-3. https://doi.org/1 0.1016/S1470-2045(15)00126-6.

41. Felip E, Hirsh V, Popat S, Cobo M, Fulop A, Dayen C, et al. Symptom and quality of life improvement in LUX-lung 8, an open-label phase III study of second-line Afatinib versus Erlotinib in patients with advanced squamous cell carcinoma of the lung after first-line platinum-based chemotherapy. Clin Lung Cancer. 2018;19(1):74-83 e11. https://doi.org/10.1016/j.cllc.2017.06.002.

42. Chen N, Fang W, Zhan J, Hong S, Tang Y, Kang S, et al. Upregulation of PDL1 by EGFR activation mediates the immune escape in EGFR-driven NSCLC: implication for optional immune targeted therapy for NSCLC patients with EGFR mutation. J Thorac Oncol. 2015;10(6):910-23. https://doi.org/10.1097/ JTO.0000000000000500.

43. Akbay EA, Koyama S, Carretero J, Altabef A, Tchaicha JH, Christensen CL, et al. Activation of the PD-1 pathway contributes to immune escape in EGFR-driven lung tumors. Cancer Discov. 2013;3(12):1355-63. https://doi. org/10.1158/2159-8290.CD-13-0310.

44. Han JJ, Kim DW, Koh J, Keam B, Kim TM, Jeon YK, et al. Change in PD-L1 expression after acquiring resistance to Gefitinib in EGFR-mutant non-smallcell lung Cancer. Clin Lung Cancer. 2016;17(4):263-70 e262. https://doi.org/1 0.1016/j.cllc.2015.11.006.

45. Rizvi NA, Chow LQM, Borghaei H, Shen Y, Harbison C, Alaparthy S, et al. Safety and response with nivolumab (anti-PD-1; BMS-936558, ONO-4538) plus erlotinib in patients (pts) with epidermal growth factor receptor mutant (EGFR MT) advanced NSCLC. J Clin Oncol. 2014;32(15 suppl):80228022.

46. Ma BBY, Rudin CM, Cervantes A, Dowlati A, Costa D, Schmid P, et al. 4410 Preliminary safety and clinical activity of erlotinib plus atezolizumab from a Phase lb study in advanced NSCLC. Ann Oncol. 2016;27:ix141.

47. Oxnard GR, Yang JC, Yu H, Kim SW, Saka H, Horn L, et al. TATTON: a multiarm, phase lb trial of osimertinib combined with selumetinib, savolitinib, or durvalumab in EGFR-mutant lung cancer. Ann Oncol. 2020;31(4):507-16. https://doi.org/10.1016/j.annonc.2020.01.013

\section{Publisher's Note}

Springer Nature remains neutral with regard to jurisdictional claims in published maps and institutional affiliations. 